\title{
Agentes Comunitários de Saúde e os sentidos de "ser agente"
}

\author{
Viviane Milan Pupin \\ Cármen Lúcia Cardoso \\ Universidade de São Paulo - Ribeirão Preto
}

\begin{abstract}
Resumo
O Programa Saúde da Família constitui-se enquanto estratégia de mudança do modelo assistencial. O artigo apresenta os resultados de uma pesquisa qualitativa sobre os sentidos de "ser agente" produzidos, por meio de entrevistas abertas, com Agentes Comunitários de Saúde que trabalham nos cinco Núcleos de Saúde da Família da cidade de Ribeirão Preto - São Paulo, vinculados à Faculdade de Medicina de Ribeirão Preto USP. As entrevistas foram gravadas e transcritas na íntegra e analisadas segundo princípios da análise de conteúdo. A análise permitiu a descrição de sentidos acerca de ser agente subdivididos em: Sentidos produzidos na relação com a comunidade e Sentidos produzidos na relação com a equipe. A análise dos sentidos de ser agente possibilitou construir um diálogo sobre as tensões relacionadas a um fazer em saúde ora permeado por concepções atreladas ao modelo biomédico, ora atrelado aos novos paradigmas em saúde.
\end{abstract}

Palavras-chave: programa saúde da família; agentes comunitários de saúde; pesquisa qualitativa

\begin{abstract}
Community Health Agents and the meanings of "being an agent". The Family Health Program consists of a strategy to change the health care model. This article presents the results from a qualitative study about the meanings of "being an agent" obtained through open interviews with Community Health Agents who work in five Family Health Centers of the Ribeirão Preto School of Medicine (University of São Paulo), located in Ribeirão Preto, São Paulo. Interviews were tape recorded, fully transcribed, and then content analyzed. The analysis allowed for descriptions of meanings toward "being an agent", subdivided into: Meanings produced by relationships with the community, and Meanings produced by relationships with the team. Analyzing the meanings of being an agent provided the establishment of a dialogue about the tensions related to a health practice that is at times influenced by conceptions associated with the biomedical method, and at other times with the new health paradigm.
\end{abstract}

Keywords: family health program; community health agents; qualitative research

$\mathrm{O}$ Sistema Único de Saúde - SUS - tem como diretrizes a descentralização na gestão de serviços, a integralização das ações, a regionalização e a hierarquização das unidades prestadoras de serviços, a participação da população na formulação, o planejamento, a execução e a avaliação das ações de saúde e o fortalecimento do papel do município. Baseia-se no pressuposto de que o acesso à saúde deve ser universal e gratuito, enfatizando ainda a necessidade de práticas mais humanizadas em saúde.

Como tentativa de consolidar as propostas do SUS, foi criado, pelo Ministério da Saúde, em 1994, o Programa de Saúde da Família que tem os seguintes princípios: atuar em caráter substitutivo das práticas convencionais de assistência à saúde, caracterizando-se como porta de entrada do sistema local de saúde e visando a integralidade e a hierarquização - compondo o primeiro nível de ações e serviços no sistema de saúde, garantindo o acesso a outros níveis de maior complexidade e responsabilizando-se pelo acompanhamento dos indivíduos e famílias em todo o processo de referência e contra-referência; territorialização e adscrição de clientela, atuando numa área específica e, conseqüentemente, favorecendo o estabelecimento de vínculos com a comunidade e possibilitando o compromisso e a co-responsabilidade tanto da equipe quanto da comunidade. A recomendação é de atuação em equipes interprofissionais, sendo que uma equipe deve ficar responsável por uma área onde residem entre 600 a 1.000 famílias, com limite máximo de 4.500 habitantes.

As equipes de saúde do PSF são compostas por um médico generalista (ou da família), um enfermeiro, um auxiliar de enfermagem, um odontólogo, um técnico em higiene bucal e quatro a seis agentes comunitários. Além disso, outros profissionais como assistentes sociais e psicólogos também 
podem ser incluídos na equipe, de acordo com as necessidades do local no qual a equipe se encontra inserida (Ministério da Saúde, 2000).

O Programa de Agente de Saúde, que teve início no Ceará em 1987, foi uma tentativa de fixar profissionais da saúde em locais sem recursos econômicos e sociais, atendendo a recomendações da Organização Mundial de Saúde de criar opções viáveis para amenizar os problemas de saúde da população (Silva, 1997).

O slogan a saúde bate à sua porta, criado pelo Governo do Ceará, destaca a importância política do Agente de Saúde, a mudança preconizada do fazer saúde e sua posição estratégica junto à comunidade, já que tem acesso aos domicílios e pode estar ligado às famílias por laços afetivos e até de parentesco (Silva, 1997).

O Ministério da Saúde (2000) define como competências para o Agente Comunitário de Saúde: o trabalho em equipe, as visitas domiciliares, o planejamento das ações de saúde, a promoção de saúde, a prevenção e o monitoramento de grupos específicos, a prevenção e o monitoramento das doenças prevalentes e o acompanhamento e a avaliação das ações de saúde.

A figura do Agente Comunitário de Saúde (ACS), inserido no PSF, emerge como um elo entre a comunidade e o sistema de saúde, uma vez que deve residir na própria comunidade em que atua. Acredita-se que por ser parte da comunidade em que vive e para quem trabalha conhece melhor as necessidades desta, compartilha um mesmo contexto social e cultural e um mesmo universo lingüístico e, portanto, está mais apto a lutar pelos direitos da comunidade. (Dirigente da Fundação Nacional de Saúde, 1991, citado por Silva \& Dalmaso, 2002).

O fato de os agentes comunitários de saúde compartilharem o mesmo contexto com a comunidade é apontado por Nunes, Trad, Almeida, Homem e Melo (2002) como decisivo no aumento da eficácia das ações de educação em saúde. Além disso, a entrada no mundo familiar é sinônimo de contato com a intimidade das pessoas, com o seu universo privado, trazendo novas construções relacionais e novos sentidos para essas relações.

Segundo Silva e Dalmaso (2002), consegue-se identificar duas dimensões principais de atuação dos ACS: uma mais política, não apenas de solidariedade à população e da inserção da saúde no contexto geral da vida, mas também no sentido de organização da comunidade e de transformação das condições de saúde; outra mais técnica, relacionada ao atendimento aos indivíduos e famílias e à intervenção para a prevenção dos agravos ou para o monitoramento de grupos ou problemas específicos.

As referidas autoras apontam, também, alguns desafios para o saber fazer e saber ser agente comunitário de saúde, dentre eles: a enorme variedade de contexto, exigindo flexibilização em sua prática e nos processos e metodologias de preparação de pessoal; a amplitude das finalidades do Programa, exigindo ora uma vertente mais assistencial e de vigilância e ora de promoção de saúde e qualidade de vida; o desenvolvimento de tecnologia de trabalho adequada às necessidades; o trabalho em equipe e a identidade do agente, compondo dimensões técnicas e políticas do trabalho.
O objetivo do presente artigo é analisar os sentidos, acerca do ser agente, construídos com Agentes Comunitários de Saúde (ACS) que trabalham em Núcleos de Saúde da Família da cidade de Ribeirão Preto, vinculados à Faculdade de Medicina de Ribeirão Preto - USP.

\section{Método}

Após a aprovação do estudo pelo Comitê de Ética em Pesquisa da Faculdade de Medicina de Ribeirão Preto - USP (Processo $n^{\circ}$ 0112/CEP-FMRP-USP) procedeu-se à realização das entrevistas. Foram sorteados dois ACS de cada Núcleo de Saúde da Família, totalizando dez entrevistas, sendo nove participantes do sexo feminino e um do sexo masculino. $\mathrm{O}$ momento da entrevista consistia numa reflexão acerca do ser agente, na redação dessas associações e na posterior exploração das mesmas.

Por meio de leituras de todas as entrevistas realizadas, duas entrevistas foram selecionadas para compor o corpus de análise por considerar que o envolvimento desses participantes com a temática foi grande e que o conteúdo das entrevistas traz sentidos relevantes ao objetivo do estudo.

Para contextualizar os participantes, alguns dados mais gerais como idade e grau de instrução foram coletados, acrescentando também as associações redigidas por eles sobre o ser agente. Cabe ressaltar que os nomes são fictícios, visando não identificar os participantes. Segue abaixo a descrição dos dois participantes:

Júlia contava com 53 anos na época da realização da entrevista. Iniciou o curso de Assistente Social, mas não concluiu. Fez o curso de Técnico em Enfermagem e estava trabalhando como Agente Comunitária de Saúde há um ano e meio. Quando indagada sobre o que vinha à sua cabeça quando pensava em ser agente redigiu, na forma de tópicos, as seguintes associações: "cadastro; vínculo; saber escutar; é um elo entre a comunidade e a equipe; vivenciar das dificuldades da área; saber passar p/ [para] equipe com sigilo; ter ética".

Roberto estava com 21 anos na época da realização da entrevista, tinha segundo grau completo e trabalhava como Agente Comunitário de Saúde há um ano. Sua associação sobre o ser agente foi "base de apoio".

A análise foi feita por meio de momentos de leitura exaustiva das transcrições, possibilitando a emergência de categorias e a posterior construção de mapas de associação de idéias que são recursos de visualização que têm, segundo Spink e Lima (2000), o objetivo de dar subsídios ao processo de interpretação e facilitar a comunicação dos passos do processo interpretativo. Após a construção dos mapas de associações de idéias, procedeu-se, com base na análise categorial de conteúdo (Bardin, 1977), a uma leitura vertical dos conteúdos das categorias. Convém ressaltar que a análise do processo, feita com base na leitura horizontal dos conteúdos, será realizada em trabalhos posteriores.

Os mapas de associação de idéias dispõem em categorias toda a transcrição da entrevista de forma contínua, ou seja, trechos da entrevista são transpostos para categorias correspondentes, mas de forma transcorrida, não alterando a seqüência e o conteúdo 
da entrevista. As categorias construídas no mapa de associação de idéias foram as seguintes: Explicações dadas pelo Agente Comunitário de Saúde sobre suas associações redigidas; Sentidos de ser agente englobando os sentidos construídos acerca do ser agente, sendo subdivididos em: Comunidade englobando os sentidos produzidos sobre o ser agente na relação com a comunidade e Equipe que se constitui pelos sentidos de ser agente como participante e, conseqüentemente, na relação com uma Equipe de Saúde.

Como embasamento teórico, utilizaram-se como referência autores da saúde coletiva como Merhy (2002), Ayres (2003), Silva Júnior (2006), dentre outros.

\section{Análise do corpus}

\section{Os sentidos de ser agente na relação com a comuni- dade}

O que trabalha com a comunidade. Júlia problematiza as limitações da atuação do Agente Comunitário de Saúde e o fato de se ter uma formação técnica e teórica não garantir nem permitir uma atuação diferente, ou seja, ela tem curso de técnica em enfermagem, mas como Agente Comunitária de Saúde não está autorizada a realizar determinados procedimentos técnicos. Além disso, Júlia enfatiza o fazer técnico - procedimentos de enfermagem como verificar a pressão - como sendo o fazer possível e recorre à ética - uma instância tida socialmente como inquestionável - para justificar sua limitação na atuação.

Às vezes um aparece e "ah, você não pode verificar a pressão?" [Júlia reproduz um diálogo com usuário] "Não. aqui eu sou agente, não verifico a pressão, não aplico injeção e não posso fazer nada". Porque, antes todo mundo me conhecia como Julia enfermeira [referindo-se ao curso de técnica em enfermagem]. Agora eu sou agente. Eu não posso fazer isso. E outro dia aconteceu isso, (...) “mas porque você não pode?" [novamente reproduz um diálogo com usuário]. "Ah, eu não posso, a ética não permite”. (Júlia, linhas 430 a 435)

tem coisas que a gente pode ta fazendo e tem coisas que a gente não pode fazer. Cada um tem o seu... limite. E a gente tem que saber respeitar esse limite também. (Júlia, linhas 441 e 443)

Júlia traz para o diálogo as limitações de sua atuação e, ao enfatizar os procedimentos técnicos como sendo o fazer possível em saúde, desvaloriza os aspectos psicossociais e de politização de sua atuação. Constitui-se uma pessoa que não pode fazer nada, uma vez que não está autorizada a realizar tais procedimentos técnicos.

Ao discorrer sobre o cuidado e relacionando-o ao predomínio da atuação pautada pela técnica, Ayres (2003) pontua os recentes avanços tecnológicos da Medicina e, como contrapartida desses avanços, a autonomização e tirania dos exames complementares, a excessiva segmentação do sujeito do cuidado, o intervencionismo exagerado e a desatenção para com os aspectos psicossociais. Enfatiza a necessidade da articulação do técnico com o não técnico, não restringindo o cuidado à criação e manipulação de um objeto, mas na criação de sujeitos portadores de necessidades e participantes na construção do projeto terapêutico.

Júlia diz da capacidade de escuta do agente e aponta ser uma atividade que requer certo conhecimento sobre a forma de realizá-la, mas a escuta é significada por ela como algo que carece de um complemento mais técnico, ou seja, Júlia enfatiza a escuta como algo que deve ser acompanhado de alguma indicação, de orientação. Neste sentido, a escuta acaba por ser impregnada do modelo intervencionista, ou seja, o agente comunitário tem que saber escutar, mas também deve saber dar uma resposta para essa escuta, dar prescrições que estão no âmbito de sua atuação, incluindo os encaminhamentos.

Você saber ouvir, a pessoa desabafar com você, conversar, aí você acaba conversando sobre outros assuntos, sobre outras terapias, convidando aquela pessoa pra tá participando do PIC [Programa de Integração Comunitária], fazer uma caminhada, a tá fazendo algum tipo de lazer, algum... tipo, bordado, alguma coisa que tem... na área pra oferecer. (Júlia, linhas 209 a 212)

É saber escutar e... saber, assim, dar algumas respostas, encaminhar naquilo que a gente tem a possibilidade de ta encaminhando pra eles né, dos recursos que a gente tem. (Júlia, linhas 222 a 224)

O fato dessa necessidade de complementar a escuta com uma ação/intervenção pode significar descrença e desvalorização própria sobre a importância da escuta ao outro. Nesse sentido, Merhy (2002), ao falar sobre tecnologias em saúde, posiciona a escuta como tecnologia leve, associando os momentos de interação às tecnologias que incorporam o trabalho vivo em ato. O trabalho técnico, por sua vez, corresponderia às tecnologias que podem incorporar o trabalho vivo em ato (tecnologias leveduras) ou podem ser a expressão do trabalho morto (tecnologias duras). $\mathrm{O}$ autor acredita na possibilidade de transformações no modo de fazer/pensar saúde através do uso das tecnologias leves, ou seja, um modelo que se centraliza nas necessidades do usuário visando o cuidado integral.

Em relação à comunidade, Júlia constrói uma postura paternalista/assistencialista. A comunidade é significada como passiva e não comprometida, uma vez que Júlia destitui a comunidade do lugar de ativa, assumindo-o para si, caracterizando-se como aquela que faz de tudo pela comunidade.

\footnotetext{
E a gente tem que tá sempre ali, lembrando "óh, tem isso, óh, eu vou te trazer. Tem exame pra você fazer. Você tem que levar o seu resultado tal dia no HC [Hospital das Clínicas], você levou?" "Ah, esqueci”. "Óh, você tem consulta tal dia”. (Júlia, linhas 353 a 356)
}

$\mathrm{Na}$ mesma direção, Roberto, dizendo de si como agente comunitário de saúde constrói os sentidos para o ser agente como aquele que presta serviços de auxílio à comunidade, tanto no que diz respeito a bens materiais (alimento) e às questões psicossociais (conversar, apoiar), quanto às questões mais ligadas à moralidade, ou seja, ele refere a si como quem assiste a comunidade, na medida em que consegue recursos para a mesma e consegue orientá-la quanto ao caminho certo a seguir. 
Que a gente ta prestando serviço pra comunidade, através de... conversar com o pessoal, de... apoiar, de... fazer... auxiliar o pessoal a... como eu posso te dizer... a seguir o caminho certo, a sair do caminho errado. (...) a gente também tem... finalidade de arrumar... de conseguir alimento pro pessoal, de... muitas coisas do gênero assim. Porque eu acho que é o auxílio que a gente faz. (Roberto, linhas 15 a 20)

A prática assistencialista e a prática da vigilância - entendida aqui como sendo a imposição de uma norma certa a seguir e a repreensão do desvio dessa norma - estão pautadas no modelo hegemônico de prestação de serviços em saúde que, segundo Silva Júnior (2006) compreende a visão do corpo humano como uma máquina, o reconhecimento da natureza biológica das doenças, o aprofundamento do conhecimento científico em partes cada vez mais específicas, a exclusão de práticas alternativas, a tecnificação, a ênfase na medicina curativa e a concentração de recursos em centros hospitalares.

Como base de apoio da comunidade, Roberto descrevese como pertencendo a ela e, portanto, compartilhando certos sentidos com a mesma. Ele aponta que essa realidade o constrói como porta de entrada para o serviço de saúde, favorecendo a busca pelo agente comunitário de saúde em primeiro lugar. Ao mesmo tempo, Roberto busca diferenciar-se da comunidade ao dizer de sua importância para a mesma e de seu cuidado especial para com a comunidade como profissional da saúde.

Agente, agente comunitário de saúde é uma... é uma... atenção especial (...) Porque a gente se sente importante pra eles, né. Apesar de ser da comunidade, a gente não tinha esse convívio. Mesmo sendo da comunidade a gente não tinha esse convívio de... de importância que a gente tem agora, né. Agora eles vê a gente diferente. Nós somos pessoas importantes pra eles. Não tem só aquele vínculo de amizade, né, mas sim aquele vínculo que... nós somos profissionais de saúde. (Roberto, linhas 46 a 52)

Roberto, portanto, se reconhece detentor de um vínculo com a comunidade que vai além da amizade, como um profissional de saúde e, conseqüentemente, diferente da comunidade. Nunes et al. (2002) comentam sobre as relações de poder na construção da identidade do agente comunitário de saúde. Esse jogo de poder estaria permeando tanto as relações com a equipe de saúde quanto com a comunidade, na medida em que o agente comunitário de saúde disputa com a equipe o seu lugar de prestígio na comunidade e fazer parte de uma equipe de saúde representa ter domínio sobre certos conteúdos e práticas biomédicas, diferenciando, assim, o conhecimento do agente comunitário de saúde do conhecimento popular, situando-o numa escala superior na hierarquia de saber da sociedade.

Ainda sobre as relações de poder, Scott (2005) aponta que o Estado, ao traçar a estratégia para mudança no modelo assistencial, faz mais do que tentar oferecer serviços universalizados, descentralizados, integrais e participativos; ou seja, sua presença incentiva também um ato de disciplinamento e vigilância, sendo os membros da equipe de saúde os responsáveis por esse exercício, mediando, assim, a relação entre Estado e cidadão.
A apropriação da voz da comunidade: o anjo da guarda e o salvador da pátria. Nos sentidos de si produzidos na relação com a comunidade, Júlia traz para o diálogo o vínculo, significando-o como uma liberdade, um respeito que a comunidade tem para com o agente de saúde, apontando ser esse vínculo construído no dia a dia através das visitas domiciliares realizadas. Responsável pela formação de vínculo com a comunidade e de escutá-la, Júlia traz a voz da comunidade e descreve-se como anjo da guarda. Portanto, como a pessoa enviada para solucionar ou buscar as soluções para os problemas da comunidade dizendo, assim, de uma comunidade que acaba por depositar no agente as expectativas de que ele realmente cumpra sua função de anjo da guarda.

Ela às vezes vem procurar o núcleo, às vezes ela procura o agente... ela quer conversar porque ela tá com outro problema (...) o que faz a pessoa às vezes relatar isso pra gente é a maneira (...) do vínculo que a gente vai adquirindo no dia a dia, a partir do cadastro que a gente faz dos pacientes (...) eles passam a ter (...) respeito pela gente, uma liberdade... (Júlia, linhas 16 a 22)

[Júlia reproduz a fala de uma usuária] "Hoje você foi o anjo da guarda que Deus me mandou. Hoje eu tava tão deprimida, precisava tanto de alguém pra vir aqui, que eu preciso tanto de conversar”. (Júlia, linhas 23 a 25)

Roberto apropria-se da voz da comunidade e descreve-se como salvador da pátria, por meio da metáfora de uma entidade superior, de alguém capaz de resolver qualquer problema e, portanto, de um transformador da realidade (pátria) caos em uma realidade (pátria) boa; colocando, portanto, a comunidade no lugar de dependente do agente e de quem sempre cobra a presença do mesmo. Porém, essa dependência da comunidade não significa para ele algo ruim, ao contrário, é sinal de afinidade e confiança que a comunidade tem na figura do agente comunitário de saúde. Portanto, Roberto ressignifica sua relação com a comunidade, ao ver na necessidade da constante presença do agente um indicativo de um vínculo estabelecido com o mesmo, dizendo, assim, de um agente que quebra-galhos para a comunidade.

E a gente tá na luta todo dia pra tentar melhorar e... sempre ajudar o pessoal da comunidade, né. Então eles vêem a gente como um salvador da pátria. (Roberto, linhas 77 a 79)

Quando a gente não vai em certa casa no mês, eles aparecem aqui e "ah, cadê o meu agente?". Reclama. E a gente tem que acabar indo, porque se não for lá no mês que vem, eles xingam a gente. Xingam, assim, chamar a atenção, né. Porque... isso mostra o tanto que eles gostam da gente e confiam na gente. (Roberto, linhas 102 a 105)

Além de ser o elo de ligação entre a unidade e a comunidade, ele traz problemas pra equipe, tentando solucionar. Ele... quebra, vamos dizer assim, quebra galho pra todas as pessoas. E... a gente procura fazer tudo da melhor forma. (Roberto, linhas 120 a 123)

Ao se reconhecerem enquanto anjo da guarda e salvador da pátria, Júlia e Roberto descrevem-se pessoas enviadas 
para solucionar ou buscar as soluções para os problemas da comunidade e dizem de uma comunidade, a qual acaba por depositar neles as expectativas de que realmente cumpram essa função. Suas descrições de si, pautadas pela voz da comunidade como figuras muito potentes, podem restringir ou até mesmo impedir possibilidades de atuações em que o papel político do agente esteja presente, uma vez que reitera a função assistencialista do ACS e a passividade da comunidade. Além disso, tal postura pode gerar um desgaste físico e emocional, marcado pela sobrecarga de atuações que os próprios ACS se impõem e pela conseqüente percepção da impossibilidade em atender a todas as demandas da comunidade.

\section{Os sentidos de ser agente na relação com a equipe}

$O$ elo de ligação e a ética do sigilo. Roberto significa o ser agente como elo de ligação, ou seja, aquele que capta informações e vivências na comunidade e passa para a equipe, dizendo ser este um movimento bilateral, ou seja, tanto o agente capta informações e leva para a equipe, quanto a equipe também compartilha informações com os agentes. Também é responsável pelo vínculo que a equipe tem com a comunidade, uma vez que divulga o serviço de saúde, constituindo-se, mais uma vez, como a porta de entrada da comunidade para com a unidade de saúde. Ser o elo de ligação também é significado como ser o mediador de relações, na medida em que o agente comunitário de saúde é construído como responsável por apaziguar as relações entre comunidade e serviço de saúde.

Nós somos o elo de ligação da equipe com a comunidade. Então... porque tudo o que acontece lá a gente traz pra cá. E também quando eles têm alguma que eles passam pra gente, por exemplo, pra gente tá por dentro, né. Então, eu acho que o... o vínculo que a equipe tem com a comunidade, a gente deve ao agente comunitário por fazer a divulgação do serviço pro pessoal. (Roberto, linhas 61 a 65 )

Apesar de ter sempre umas pessoas que falam mal do serviço, mas a gente é aquela pessoa que sempre tá em cima, que "não, não é assim. É porque acontece isso e aquilo". Tentando sempre remediar a situação. Eu acho que isso é freqüentemente que a gente faz. (Roberto, linhas 70 a 72 )

Nunes et al. (2002) referem a função do agente comunitário de saúde como o elo entre a comunidade e o sistema de saúde, apontando que a facilitação dessa função estaria no fato de o agente residir no local onde trabalha, compartilhando, assim, o mesmo universo cultural e lingüístico da comunidade. Além disso, o fato de realizarem visitas domiciliares e entrarem em contato com o universo privado das famílias, faz com que a relação entre agente e comunidade seja mais próxima e com que novos sentidos sejam construídos nessa relação. Cabe aqui problematizar essa função de elo do agente comunitário de saúde: ao mesmo tempo em que o trazer informações para a equipe pode transformar o agente comunitário num mero receptor e transmissor de informações, pode também transformálo num mediador de relações entre a comunidade e a equipe, caracterizando-o como porta de entrada para as insatisfações dos usuários com o serviço e o encarregado de deixar a população conformada com as condições do serviço que utiliza.

$\mathrm{Na}$ direção de Roberto, Júlia ressignifica o que considera ser a função de elo entre a comunidade e equipe. Vê no vínculo estabelecido a condição para a obtenção de informações mais íntimas e de caráter mais sigiloso, ao mesmo tempo em que esse vínculo a faz problematizar a questão da ética/sigilo, permitindose quebrar essa ética / sigilo em situações em que outras pessoas estão envolvidas. Porém, para isso, espera contar também com o sigilo da equipe. Portanto, Júlia relata momentos em que considera que não deve compartilhar com a equipe informações obtidas nas visitas domiciliares e outros em que considera fundamental ocorrer a troca de informações - quando outras pessoas possam ser afetadas. Júlia problematiza a questão do para quem o usuário contou a informação e com quem ele vinculouse, ou seja, para conseguir certas informações, pressupõe-se a existência de um vínculo entre agente e usuário e relatar todas as informações à equipe poderia significar a quebra desse vínculo caso não se tenha garantido o sigilo de toda a equipe. Além disso, essa quebra de sigilo pode significar para ela a quebra do respeito à intimidade do outro, como uma traição por parte dela para com a comunidade.

As famílias passam a ter mais um vínculo com a gente (...) eles passam a ter liberdade de estar contando mais certas coisas pra gente, certo sigilo, certo segredo deles. (Júlia, linhas 136 a 138)

É uma responsabilidade muito grande. É uma ética muito grande, porque tem muitas coisas, (...) a gente não pode tá relatando tudo. Eu principalmente... tem muitas coisas que eu não coloco no relatório. Porque se ela confessou aquilo pra mim e pediu pra que eu não comentasse, quer dizer, é uma coisa dela, que ela quis desabafar, conversou comigo, falou tudo que tinha. Às vezes já fez algum aborto, às vezes ela provocou e... ela nunca contou isso pro médico, e pra gente ela chegou, me contou tudo certinho, como é que foi, o que que ela fez. (...) Porque às vezes algumas coisas a gente tem que passar, mas tem que ser com sigilo. (...) Porque eu posso ta passando um sigilo de um paciente, de uma família desde que esteja envolvido mais alguém da família nesse problema. (Júlia, linhas 150 a 167)

Concordamos com Fortes e Spinetti (2004) em que os ACS têm acesso a muitas informações pessoais dos usuários e que existem dificuldades em se limitar tal acesso, uma vez que os usuários, na maioria das vezes, revelam as condições de sua saúde primeiramente aos agentes, gerando conseqüentemente um dilema ético, já que o contato com certas informações pode trazer algum grau de estigmatização e/ou discriminação para os usuários. Tais autores questionam a necessidade de o agente repassar para a equipe todas as informações recebidas através do vínculo estabelecido, o que poderia ferir, assim, a esfera de confiabilidade construída entre agente comunitário de saúde e usuário.

O insatisfeito com a remuneração. A narrativa de Roberto é permeada por suas perspectivas futuras com relação à profissão, apontando a falta de estímulo para o trabalho, relacionando-a a uma baixa remuneração do agente comunitário de saúde. Para justificar esse baixo salário, Roberto refere-se a funções 
que até então não havia mencionado como sendo as de um agente comunitário - funções mais médicas como cuidar de hipertenso e de diabéticos, trazendo para o diálogo a questão da responsabilidade para com doenças e o baixo salário.

A gente não é tão bem remunerado, como eu acho que... pelas... pelas responsabilidades que nós temos. Cuidar de hipertenso, cuidar de diabético, correr atrás de criança, de... das várias tarefas que nós temos. (Roberto, linhas 91 a 93)

Roberto aponta sua satisfação em ajudar as pessoas e, ao mesmo tempo, sua insatisfação salarial e sua preocupação com o futuro, afirmando que ganhar trezentos reais por mês não será suficiente, apontando algumas perspectivas de mudanças com relação a sua profissão, tais como: a existência de regulamentação da profissão e de sindicatos atuantes, que considera mudar o futuro de sua profissão.

Ah, deve ter assim, regulamentações da profissão. Precisa de... não sei, de um sindicato atuante, que a gente não tem. E outras coisas. (Roberto, linhas 131 e 132)

Sobre o sentimento de desvalorização financeira do trabalho do agente comunitário de saúde, Nunes et al. (2002) apontam que a inserção do agente comunitário de saúde na equipe do Programa Saúde da Família representou um aumento significativo de trabalho e responsabilidade, sem que isso tenha sido acompanhado de aumento salarial correspondente. Acrescentam que a situação torna-se ainda mais crítica quando se compara o salário do agente comunitário de saúde com o de outros membros da equipe. $\mathrm{O}$ fato de que os profissionais melhor remunerados são aqueles que realizam procedimentos técnicos justifica a reivindicação de aumento salarial dos agentes comunitários de saúde pautada pela voz do discurso biomédico - enfatizando o cuidar da doença - já que essa é a atuação valorizada social e financeiramente.

\section{Discussão}

Refletir acerca dos sentidos de ser agente nos permite perceber que a constituição do ACS como tal caracteriza-se como um processo, ou seja, não existe um agente comunitário de saúde a priori, mas ele se constitui agente a partir de suas vivências no cotidiano do trabalho que, por sua vez, é contextualizado sócio-historicamente.

O cuidado, trazido para o diálogo na relação do agente comunitário de saúde com a comunidade, é enfatizado em seu lado técnico, ou seja, procedimentos técnicos significam a forma possível de oferecer o cuidado ao outro, enquanto que procedimentos relacionais como a escuta e o acolhimento não ocupam o lugar de tecnologias em saúde.

Além disso, o cuidado foi construído como prática assistencialista, na qual os agentes comunitários de saúde ocupam o lugar de quem detém um certo poder pelo conhecimento biomédico que adquirem no trabalho que os diferencia da comunidade. Esse poder por sua vez os constrói enquanto anjo da guarda e salvador da pátria. Ao assumirem o lugar de anjo da guarda e salvador da pátria, colocam a comunidade no lugar de quem é carente e precisa de alguém que faça as coisas por ela. Sendo assim, ao construir o sentido de ser agente como muito potente e da comunidade como carente e dependente, suas possibilidades de atuação acabam se restringindo a posturas assistencialistas e intervencionistas. A dimensão política de seu papel acaba ficando mais restrita à solidariedade, estando pouco presente a questão de que o agente é alguém que conhece a comunidade e seus recursos e de que participa de um equipamento de saúde, podendo utilizá-los visando transformar as condições de vida.

Acreditamos que a valorização de um fazer técnico pode estar vinculada à questão da remuneração, uma vez que os profissionais da Equipe de Saúde da Família que tradicionalmente são os responsáveis pelas doenças são mais bem remunerados.

Cabe de fato problematizar a questão salarial: qual a lógica que estaria permeando a atribuição salarial para cada um dos profissionais envolvidos no Programa Saúde da Família e como essa lógica estaria permeando os sentidos de ser agente?

Os Agentes Comunitários de Saúde, tendo em vista a diferença salarial, vêem na sua profissão uma porta de entrada para o trabalho no serviço de saúde, buscando na profissionalização e na conseqüente incorporação de saberes técnicos a expectativa de crescimento profissional e financeiro.

Júlia e Roberto trazem novos sentidos para o ser um elo entre a comunidade e a equipe. Ser membro da comunidade pode facilitar a inserção do agente comunitário de saúde no domínio familiar, assim como pode dificultar e trazer implicações para o profissional agente, uma vez que ele não deixa de estar presente em outros momentos da vida comunitária. Para os outros profissionais da saúde, vinculados ao Programa Saúde da Família, os espaços de atuação profissional e da vida pessoal estão mais delimitados, ao passo que para o agente comunitário de saúde esses espaços acabam sendo o mesmo. O que pode ser sentido como um facilitador das relações com a comunidade, também pode trazer a necessidade de se pensar em outros sentidos possíveis que esse pertencer à comunidade implicaria, como por exemplo, ser a porta de entrada também para as insatisfações da comunidade e estar muito envolvido com a mesma, implicando em dificuldades para o agente comunitário de saúde.

Para além das novas contribuições do entrar no universo privado das famílias, a análise das entrevistas com os Agentes Comunitários de Saúde possibilitou refletir sobre outros sentidos que esse fato possa ter para toda a equipe e até mesmo para a família usuária do PSF. Por ser formada por no mínimo quatro pessoas que são da comunidade (o número mínimo de Agentes Comunitários de Saúde na Equipe de Saúde da Família), as relações de parentesco e afinidades entre os agentes que compõem a equipe e a comunidade tornam ainda mais complexa a forma de lidar em equipe com os dados obtidos. Isto porque o limite entre o profissional e o pessoal encontra-se fusionado, correndo o risco, dessa forma, de estigmatizar as famílias, de usar as informações para realizar um controle moral e até mesmo como fofoca, comprometendo assim a atuação não só do Agente Comunitário de Saúde, mas da equipe como um todo. O fato dificulta o avançar para processos que envolvam co-responsabilização e cuidado com a saúde do outro por parte 
dos profissionais de saúde.

Através desse estudo explicitamos sentidos que esses agentes estão produzindo, com o intuito de não tomar os discursos e expectativas sobre os Agentes Comunitários de Saúde como algo dado a priori e imutável, mas sim como discursos produzidos sócio-historicamente e que passam constantemente por ressignificações, nas quais a construção dos sentidos de ser agente implica num questionamento de conceitos e expectativas sobre o fazer em saúde e sobre o Agente Comunitário de Saúde.

\section{Agradecimento}

As autoras agradecem o apoio da Fundação de Amparo à Pesquisa do Estado de São Paulo (FAPESP).

\section{Referências}

Ayres, J. R. C. M. (2004). Cuidado e reconstrução das práticas de saúde. Interface - Comunicação, Saúde, Educação, 8, 73-92.

Bardin, L. (1977). Análise de conteúdo. Lisboa: Edições 70.

Fortes, P. A. C., \& Spinetti, S. R. (2004). O agente comunitário de saúde e a privacidade das informações dos usuários. Caderno de Saúde Pública, 20,
1328-1333.

Merhy, E. E. (2002). Saúde: a cartografia do trabalho vivo. São Paulo: Hucitec.

Ministério da Saúde (2000). Cadernos de Atenção Básica. Programa Saúde da Família. Brasília: Autor.

Nunes, M. O., Trad, L. B., Almeida, B. A., Homem, C. R., \& Melo, M. C. I. C. (2002). O agente comunitário de saúde: construção da identidade desse personagem híbrido e polifônico. Caderno de Saúde Pública, 18, 16391646.

Scott, P. (2005). Gênero, família e comunidade: observações e aportes teóricos sobre o Programa Saúde da Família. In W. Villela \& S. Monteiro (Orgs.), Gênero e saúde: PSF em questão (pp.73-93). Rio de Janeiro/ Brasília: ABRASCO \& UNFPA.

Silva, J. A., \& Dalmaso, A. S. W. (2002). O agente comunitário de saúde e suas atribuições: os desafios para os processos de formação de recursos humanos em saúde. Interface - Comunicação, Saúde, Educação, 6, 75-83.

Silva, M. J. (1997). Agente de Saúde: agente de mudança? - A experiência do Ceará. Fortaleza: Fundação Cearense de Pesquisa e Cultura.

Silva Júnior, A. G. (2006). Modelos tecnoassistenciais em saúde: o debate no campo da Saúde Coletiva. São Paulo: Hucitec.

Spink, M. J., \& Lima, H. (2000). Rigor e visibilidade: a explicitação dos passos da interpretação. In M. J. Spink (Org.), Práticas discursivas e produção de sentidos no cotidiano: aproximações teóricas e metodológicas (pp. 93-122). São Paulo: Cortez.

Viviane Milan Pupin, psicóloga, é mestre em Psicologia pela Faculdade de Filosofia, Ciências e Letras de Ribeirão Preto da Universidade de São Paulo. Endereço para correspondência: FFCLRP - USP, Departamento de Psicologia e Educação; Avenida Bandeirantes, 3900; Ribeirão Preto, SP; CEP: 14.040-901. Tel.: (16) 3602-3660. E-mail: vivianepupin@pg.ffclrp.usp.br

Cármen Lúcia Cardoso, doutora em Psicologia pela Faculdade de Filosofia, Ciências e Letras de Ribeirão Preto da Universidade de São Paulo, é docente no Departamento de Psicologia e Educação da mesma instituição. E-mail: carmen@ffclrp.usp.br 